\title{
O Corpo como Interface: Latour e um aprendizado menos afirmativo
}

\author{
The Body as Interface: Latour \\ and a less affirmative art school \\ Arlette Souza e Souza ${ }^{1}$ \\ Fátima Costa de Lima ${ }^{2}$
}




\section{Resumo}

Este artigo propõe relacionar a noção de mente incorporada desenvolvida nas ciências cognitivas por George Lakoff e Mark Johnson, com a discussão levantada por Bruno Latour sobre o modo como descrevemos o corpo. A partir destes dois pontos de vista, discutimos o discurso como manifestação do corpo e os processos mentais como veículo de associação entre mundos, corpos, objetos e sentidos diferentes. Diante destas considerações questionamos o papel do corpo nos estudos científicos, também a partir da perspectiva de Latour.

Palavras-chave: Aprendizado; ciências cognitivas; estudos científicos

\section{Abstract}

This article relates the notion of "embodied mind" developed in cognitive science by George Lakoff and Mark Johnson with Bruno Latour's (2008) discussion about the way we describe the body. From these two points of view, we discuss the speech as a body manifestation and the mental processes as a way of associating different worlds, bodies, objects and senses. In the light of such considerations, we question the role of the body in the scientific studies, also from Latour's perspective.

Keywords: Learning; cognitive science; scientific studies

ISSN: 1414.5731

E-ISSN: 2358.6958

${ }^{1}$ Mestranda do Programa de Pós-Graduação em Teatro (PPGT), Centro de Artes, da Universidade do Estado de Santa Catarina (UDESC). arlettesouza@gmail.com

${ }^{2}$ Prof. Dra. Assistente do Programa de Pós-Graduação em Teatro (PPGT), e na graduação em Teatro, Centro de Artes, da Universidade do Estado de Santa Catarina (UDESC). costadelimafatima@gmail.com 


\title{
O corpo em Latour
}

O filósofo Bruno Latour ${ }^{3}$ (2008) investiga uma forma de descrever o corpo, não através da definição de sua natureza ou de sua "essência", mas percebendo suas afecções e como este se relaciona com o mundo à sua volta:

\begin{abstract}
Armados com uma definição tão «pato-lógica» de corpo, livramo-nos da obrigação de definir uma essência, uma substância (o que o corpo é por natureza). Em vez disto, como argumentarei neste artigo, podemos procurar definir o corpo como um interface que vai ficando mais descritível quando aprende a ser afetado por muitos mais elementos. O corpo é, portanto, não a morada provisória de algo de superior - uma alma imortal, o universal, o pensamento - mas aquilo que deixa uma trajetória dinâmica através da qual aprendemos a registrar e a ser sensíveis àquilo de que é feito o mundo. (Latour, 2008, p. 40)
\end{abstract}

Latour (2008) explica que ter um corpo é "aprender a ser afetado" (Latour, 2008 p. 39). Ele utiliza o argumento de Vinciane Despret para explicar que ter um corpo é ser colocado em movimento, é ser movido, é ser colocado em relação a outros objetos (humanos ou não). E, além disso, neste processo de aprendizado, o corpo vai se tornando cada vez mais preciso, definível ou narrável. O contrário seria estar paralisado, apático, impassível, morto, a definição patológica a qual ele se refere. Neste argumento ele explica que não está tratando da essência do corpo, de seu cerne ou fundamento. Pelo contrário, o autor pretende definir o corpo através de como este se relaciona ou de como se sensibiliza, ao encontrar-se com outros elementos do mundo.

Latour (2008) ainda descreve o corpo como o plano no qual nos conectamos, nos comunicamos com o mundo, ou a "trajetória dinâmica" (Latour, 2008, p. 39) mencionada anteriormente, onde ocorre o aprendizado de ser afetado, o aprendizado da sensibilidade. O corpo como uma Interface "que vai ficando mais descritível quando aprende a ser afetado por muitos mais elementos" (Latour, 2008 p. 39). Como um campo de interação, ou de associações que está em processo de aprender a se modificar, e, portanto, de questionar aquilo que é fixo e indelével em sua narrativa. "Adquirir um corpo é um empreendimento progressivo que produz simultaneamente um meio sensorial e um mundo sensível". (Latour, 2008 p. 40)

Este aprendizado modifica o corpo e permite que este habite um novo ambiente diferenciado, pois o entorno passa a ser percebido de forma diferente. Neste processo, o corpo é um espaço onde as percepções se dinamizam, e o meio, ao mesmo tempo, se amplia devido a própria dinâmica do corpo.

$\mathrm{O}$ autor reconhece a dificuldade em descrever ou em relatar o corpo. Ele decide então, voltar o olhar para a noção de body talks, as conversas, as falas, os discursos do corpo, isto é, "como o corpo é envolvido nos relatos daquilo que faz" (Latour, 2008 p. 40). Como o corpo abraça ou engloba seus discursos e o que, então, o corpo aprende com estes afetos?

A partir da constatação de que estamos sempre em relação, o autor se pergunta qual seria o sentido de "aprender a ser afetado"? (Latour, 2008 p. 40). Para começar

${ }^{3}$ Bruno Latour é sociólogo, antropólogo e filósofo francês, professor do Instituto de Estudos Políticos de Paris. 
a responder esta pergunta, ele descreve o exemplo do chamado treinamento de "narizes" de Geneviève Teil. Nas indústrias de perfume francesas, os conhecedores de cheiros, os especialistas em fragrâncias e os aprendizes devem passar por um treinamento, de apenas uma semana de duração, para aprimorar sua capacidade de distinguir cheiros, conseguindo a proeza de reconhecer diferenças muito sutis entre os aromas. Este treinamento utiliza um "kit de odores", que é uma sequência de cheiros, bem distintos, diferentes entre si, que vão desde o aroma mais suave até o mais forte. A partir deste treinamento com o "kit de odores", o corpo aprende a ter um nariz mais sensível que permite a percepção de um novo mundo de cheiros, bem diferente daquele anterior ao treinamento. Os aprendizes ganham um novo nariz, um novo jeito de sentir cheiros e aprendem a registrar o mundo de uma maneira nova e, ao mesmo tempo, o mundo se transforma para esta pessoa, que terá um nariz sensível a cheiros que não existiam antes do aprendizado.

Não é por acaso que se chama «nariz» a esta pessoa. Tudo se passa como se pela
prática ela tivesse adquirido um órgão que define a sua capacidade de detectar
diferenças químicas ou outras: pelo treino, aprendeu a ter um nariz que lhe per-
mite habitar num mundo odorífero amplamente diferenciado. As partes do corpo,
portanto, são adquiridas progressivamente ao mesmo tempo que as "contrapar-
tidas" do mundo vão sendo registadas de nova forma. Adquirir um corpo é um
empreendimento progressivo que produz simultaneamente um meio sensorial e
um mundo sensível. (Latour, 2008 p. 40)

Latour trabalha com universos diferentes, nariz/cheiros, corpo/mundo, e fala do aprendizado de relacioná-los entre si, de traduzi-los em algo novo, transformando -os e, em contrapartida, transformando o mundo. É possível também perceber nesta ideia, a questão da construção de novos discursos e de novos sujeitos enquanto as relações acontecem. O filósofo não quer definir o corpo usando de dualismo, de oposição ou de submissão e também não o descreve holisticamente, considerando o corpo como um todo, como um organismo. Ele busca uma forma de relatar o corpo mais ampla, na qual possamos usar "proposições (que são articuladas ou desarticuladas) em vez de afirmações (que são verdadeiras ou falsas) " (Latour, 2008 p. 40).

As proposições de Latour evocam um sujeito (ou humano) em contato com o mundo, cada vez de uma nova maneira. Um sujeito desarticulado, para Latour, é aquele que sempre responde igual. Independente do estímulo a que é submetido, sempre exibe o mesmo comportamento. Por outro lado, um sujeito articulado aprende a ser afetado pelo outro e não apenas por si próprio. Ser articulado é ser afetado por diferenças. As afirmações são fixas e permanentes. Afirmar é replicar o original. A vantagem da articulação sobre a afirmação é que a articulação nunca termina, nunca chega a uma conclusão definitiva, está sempre se auto investigando. O argumento de Latour é que articulações criam novas articulações. "Quanto mais mediações melhor para adquirir um corpo, para se tornar sensível aos efeitos de mais entidades diferentes" (Latour, 2008 p. 45). Portanto, o autor propõe um modelo diferente: não mais um corpo/sujeito, um mundo/objeto e um intermediário/conector deste sujeito com o mundo, mas um conjunto de associações, ou de relações.

Latour considera o "kit de odores" como uma coextensão do corpo. Ele funciona junto com o professor ou especialista, sensibilizando o corpo para as diferenças 
de odores. Porém, não guia os aprendizes a um estado de consciência ou de atenção, mas faz com que os alunos criem coisas diferentes a cada vez, ensinando a ser afetado e a efetuar, através do fazer. "Antes do treino, os odores atingiam os alunos, mas não os faziam agir, não os faziam falar, não os tornavam atentos, não os excitavam de formas precisas: qualquer grupo de odores produziria nos alunos o mesmo efeito ou afeto geral e indiferenciado" (Latour, 2008 p. 41). O autor explica que a articulação é diferente de autoridade, e também da repetição a qual vem a reboque de uma posição impositiva. Para Latour, quanto mais controvérsias mais o corpo é propositivo ou articulado.

A questão que ele coloca é que as proposições podem ser bem ou mal articuladas. Latour, analisando a obra de Isabelle Stengers e Vinciane Despret, resume uma epistemologia normativa alternativa: o conhecimento científico é um acontecimento raro, interessante e arriscado e tem sempre que recomeçar a cada nova proposição. “O princípio geral de S-D ${ }^{4}$ então fica assim: concebe as tuas pesquisas de forma a que maximizem a recalcitrância daqueles que interrogas" (Latour, 2008 p. 50). Neste sentido, ele explica que os humanos, quando confrontados com a autoridade cientifica, têm uma tendência a perder sua resistência, sua possível recusa a seguir padrões e, ao invés disso, vale-se apenas de afirmações redundantes.

Para o filósofo francês, o próprio fenômeno deve propor suas questões, e quando o fenômeno de estudo é relacionado ao ser humano, as repetições geralmente se sobrepõem as diferenças nos estudos científicos. Esta é uma ocorrência que pode ser observada tanto nos laboratórios de pesquisa, como nas salas de aula: uma afirmação científica carrega em si uma calcificação nos questionamentos. Para Latour (2008), ainda enfrentamos na sala de aula a hierarquia do saber. Num espaço de pesquisa ou na academia, o mais importante é que o novo repertório de ações deve diferir daquele com o qual começamos, e geralmente, este é o critério primordial para que a pesquisa seja considerada positiva.

Científico, nas mãos de S\&D, é um adjetivo que define uma articulação entre proposições permitindo que estas sejam mais articuladas. Isto é, que produzam «diários» e «bonecos» menos redundantes, modificando cada vez mais os ingredientes que compõem o multiverso, o seu repertório de ações, as suas competências e performances e, assim, as questões que suscitam entre todos aqueles, cientistas e não-cientistas, que com eles contactam. (Latour, 2008 p. 53)

Para Latour (2008), existe um desejo de descobrir uma generalização que englobe todas as hipóteses e possibilidades para que, somente então, se possa fazer uma afirmação científica. A questão que o autor coloca é que no processo de investigação de explicações gerais surge uma tendência a eliminar versões alternativas e a tratar as diferenças restantes como irrelevantes e os rastros apenas como dejetos. Para que um protocolo seja considerado científico, normalmente é importante que o cientista interfira o mínimo possível no processo de pesquisa. "O ideal comum de ciência é então composto por um cientista desinteressado que deixa entidades completamente mudas e não-interferidas percorrerem automaticamente sequências de comportamento" (Latour, 2008, p. 51). Ao invés deste, de acordo com S-D em Latour 
(2008), na verdade, é preciso um cientista engajado e interessado, que proporciona ao seu objeto de estudo as oportunidades necessárias para responder às questões que o objeto suscita.

\section{A mente incorporada}

Em uma outra perspectiva, o linguista George Lakoff 5 e o filósofo Mark L. Johnson ${ }^{6}$ (1999), no livro Filosofia da Carne $^{7}$ (tradução nossa) tem o intuito de superar algumas questões da filosofia ocidental através das descobertas das ciências cognitivas. As ciências cognitivas tratam do sistema conceitual humano e englobam pelo menos seis disciplinas: a psicologia, a antropologia, a filosofia, a neurociência, a inteligência artificial e a linguística. É um campo relativamente novo que vem se desenvolvendo desde os anos 1950.

Para este artigo é relevante o momento em que os autores explicam que os conceitos e a razão são incorporados. Mais especificamente, eles explicam que a razão e o conceito são atributos ou manifestação do corpo e que estes processos não apenas se localizam em nosso corpo/mente. Os cientistas cognitivos discutem como o sistema perceptivo e o sistema sensório-motor se inter-relacionam com o mundo e, a partir desta interação, fundamentam tipos particulares de conceitos linguísticos que utilizamos em nosso cotidiano.

Segundo os cientistas cognitivos Lakoff e Johnson (1999), conceitos básicos e abstratos são, em sua grande parte, metafóricos e em sua maioria, inconscientes. Além disso, são fundamentados na forma como percebemos nosso corpo e como nos relacionamos com o mundo. Para os autores, a razão tem uma relação intrínseca com a percepção e com o movimento corporal, quer dizer, a razão se origina do corpo e se utiliza dele para se modificar, se transformar através do aprendizado.

Portanto, para os autores a ideia de mente incorporada ultrapassa a ideia de que o corpo é necessário para que o pensamento ocorra. Para eles, os conceitos surgem como resultado da estrutura cerebral e corporal e de como estas propriedades se manifestam nas relações interpessoais e no mundo físico. Consequentemente, Lakoff e Johnson (1999) explicam que se a mente é incorporada, o mesmo sistema neural que estrutura a percepção, os movimentos corporais, e a manipulação de objetos também está profundamente engajado com a concepção, com as ideias, com a criação de conceitos e com a razão.

Para os autores, sistema sensório-motor estrutura a experiência subjetiva. Associamos a ideia de "muita quantidade" com a ideia de "para acima" porque vivenciamos esta correlação no nosso dia a dia. Por exemplo, quando enchemos um copo com água e percebemos que o nível sobe. A partir desta junção entre a verticalidade e a quantidade, outras metáforas secundárias aparecem, como "Os preços subiram" ou "Ele alcançou um alto patamar em sua carreira". As metáforas básicas se associam para formar as metáforas mais complexas.

\footnotetext{
${ }^{5}$ George Lakoff é professor de Linguística na Universidade da Califórnia em Berkeley

${ }^{6}$ Mark L. Johnson é professor de Filosofia na Universidade de Oregon

${ }^{7}$ Phylosophy in the Flesh: The Embodied Mind and its Challenge to Western Thought
} 
Associamos, a importância de algo com a noção de tamanho: "Amanhã será um grande dia" ou um julgamento de valor com o sentido do olfato: "Aquele político fede", calcados em nossas experiências diárias. Vamos moldando nosso discurso através destas sensações corporais inconscientemente. Segundo os autores, unimos a ideia de importância com grandeza porque, por exemplo, desde pequenos percebemos que coisas grandes são importantes. Como na relação com nossos pais, nossa mãe e/ou nosso pai têm grande importância para nós quando somos pequenos. Combinamos aquilo que é ruim com o mau cheiro, pois desejamos estar distantes de um odor que nos repele.

É importante ressaltar que os autores são linguistas e filósofos e seu objeto de estudo é o discurso, mas que, segundo eles próprios, nem sempre as metáforas se manifestam através do discurso, algumas se manifestam através do gesto, da arte ou do ritual. Por outro lado, estas metáforas não linguísticas também podem se expressar posteriormente através do discurso ou de símbolos, já que, na perspectiva de Lakoff e Johnson o discurso também é um atributo do corpo.

Para os autores, a mente é incorporada e, portanto, a razão se origina das formas corporais de inferência. A criação de conceitos está intimamente pautada na maneira como funcionamos significativamente no mundo e como criamos sentido para este, via estruturas corporais e imaginativas.

A ciência cognitiva, a neurociência e a biologia estão engajadas ativamente em caracterizar a natureza dos seres humanos. Estas caracterizações da natureza humana não se baseiam na teoria clássica das essências. A natureza humana é conceitualizada, ao invés disso, em termos de variação, mudança e evolução, e não meramente em termos de uma lista fixa de características centrais. É parte de nossa natureza variar e mudar. (Lakoff, Johnson, 1999, p. 557)

O paradoxo que se apresenta é que, se o corpo está profundamente engajado na formação do discurso, como é possível um discurso do corpo sem pré-julgamentos? A resposta cognitiva é que o conceito de corpo e o próprio corpo se modificam a cada novo engajamento no mundo, a cada novo encontro. Então, é possível pensar que estes discursos variáveis se conectam com o processo de aprendizado que descreve o espaço de interseção, ou a interface que Latour chama de corpo. Através do aprendizado o corpo se modifica, modificando, ao mesmo tempo, o seu entorno. Para mais, é possível também relacionar a ideias de Latour com as de Lakoff e Johnson sobre o engajamento do corpo na construção de novas associações, de conceitos e seu papel na racionalização.

Como Lakoff e Johnson (1999) explicam, a percepção do discurso metafórico do corpo pode alargar o campo de possibilidades de conexão no mundo. Além disso, pode criar novos discursos neste processo de mudança, se estimulado a modificar padrões de associação pois, a cada novo aprendizado, o meio se amplia, criando novas possibilidades narrativas.

\footnotetext{
${ }^{8}$ Cognitive science, neuroscience, and biology are actively engaged in characterizing the nature of human beings. Their characterizations of human nature do not rely on the classical theory of essences. Human nature is conceptualized rather in terms of variation, change, and evolution, not in terms merely of a fixed list of central features. It is part of our nature to vary and change. (Tradução nossa)
} 


\section{O corpo e o aprendizado}

A partir das considerações de Latour e de Lakoff e Johnson, é possível questionar o engajamento do corpo nos processos de aprendizado acadêmicos e nas pesquisas científicas. Latour (2008) explica que o aprendizado ainda se baseia, em grande parte, em seu sentido ou significado. O motivo pelo qual estamos ensinando ou aprendendo ainda é um ponto crucial. $O$ autor especifica que, na academia, ainda é possível perceber a carência de um ensino onde a finalidade seja o próprio processo e não uma imposição do professor ou do método. Se envolver mais no processo exige do professor que ele não afirme de antemão quais as características do processo serão ou não importantes para os seus alunos. Além disso, exige um professor que também aprenda a se sensibilizar com os materiais à sua disposição, humanos ou não. Que entenda que seu corpo, e não somente o dos alunos, também se ampliará durante o processo de aprendizagem.

No livro A Esperança de Pandora: Ensaios sobre a Realidade dos Estudos Científicos (2001), Latour discute os estudos científicos explorando o que é realidade e o que é construção e revê a dicotomia sujeito/objeto inserindo a ideia de humano e não humano, através de uma perspectiva relativista.

O problema para o cientista prático é que as habilidades exigidas para essa segunda atividade são inteiramente diferentes das exigidas para a primeira. Um pedólogo pode ser exímio na arte de cavar fossos e preservar minhocas em frascos no meio da floresta, mas absolutamente nulo ao escrever artigos. E, no entanto, é preciso fazer as duas coisas". (Latour, 2001, p. 122)

Para Latour (2001), é possível perceber que as respostas e afirmações são o caminho que percorremos normalmente nos processos de estudos científicos. Os processos de aprendizagem se estabelecem em torno de uma imposição institucional e mercadológica, que acaba por impor uma distância entre o sujeito e o objeto de estudo e, além disso, se afasta do princípio de aprendizado de sensibilidade de Latour e da ideia de um corpo mais articulado que não responde da mesma maneira a diferentes estímulos.

Por que trocar sempre um comandante por outro? [...] no âmbito das técnicas, ninguém se acha no comando - não porque a tecnologia é que se ache no comando, mas porque, verdadeiramente, nada nem ninguém comanda, nem sequer um campo de força? Estar no comando ou ser senhor não é propriedade de humanos e de não-humanos - nem de Deus. Cuidava-se que essa fosse uma propriedade de objetos e sujeitos, mas nunca funcionou: as ações sempre transbordam de si mesmas, daí se seguindo de enormes complicações. (Latour, 2001, p. 340-341)

Como explicamos no começo deste artigo, Latour (2008) descreve o corpo como um campo de interação, que ao aprender a se modificar, questiona tudo aquilo que é fixo e permanente em sua narrativa. O filósofo explica que um corpo articulado é oposto à autoridade pois questiona, está sempre em relação e, consequentemente, em transformação. 


\section{Conclusão}

Percebemos, através das perspectivas de Lakoff, Johnson e Latour, que o corpo se transforma e, consequentemente modifica o seu entorno durante os processos de aprendizado, e que, além disso, Latour defende um corpo mais articulado e menos afirmativo durante o desenvolvimento de estudos científicos. Segundo Latour (2001) a experiência e a realidade geralmente não são levadas em consideração quando tratamos de estudos científicos. Como o pedólogo descrito anteriormente, a área da pesquisa ainda convive com um abismo entre a teoria e a prática.

Lakoff e Johnson (1999) explicam que a criação de conceitos é a maneira como nos comunicamos, e, se pensarmos no corpo afirmativo de Latour, é possível perceber que a questão que surge é que, se o corpo ainda é desarticulado e afirmativo, então apenas repetimos conceitos e não criamos novas maneiras de vivenciar as transformações que viriam a reboque dos processos de aprendizagem. Estamos mais preocupados em repetir do que deixar que o processo de aprendizado realmente seja transformador, pois estamos acostumados a seguir padrões.

Além disso, Latour (2008) afirma que as controvérsias criam corpos mais articulados. Já que é na diferença, no momento em que a controvérsia surge, que o aprendizado se amplia, é possível buscar o que poderíamos entender como um diálogo de afecções, onde todos humanos e não humanos se afetam, lidando com as diferenças, dentro de um sistema onde este diálogo fluido ainda não foi estabelecido? Como perceber que possuir um corpo se relaciona com movimento, com a relação com outros "objetos" (humanos ou não) e que isto se opõe a permanência e a fixidez que buscamos durante o desenvolvimento de pesquisas científicas, que segundo Latour (2008), só resultaria numa definição de corpo mais patológica e paralítica? Como vivenciar um espaço acadêmico onde as articulações e proposições sejam mais valorizadas que as afirmações?

\section{Referências}

LAKOFF, G. JOHNSON, M. Philosophy in the Flesh: The Embodied Mind and its Challenge to Western Thought. New York: Basic Books, A Member of the Perseus Books Group, 1999.

LATOUR, B. Capítulo 1 Como falar do corpo? A dimensão normativa dos estudos sobre a ciência. IN: Objectos Impuros: Experiências em Estudos sobre a Ciência. Porto: Afrontamento, 2008.

A Esperança de Pandora: Ensaios sobre a Realidade dos Estudos Científicos. Bauru, SP: EDUSC, 2001.

Recebido em: 15/07/2017

Aprovado em: 26/11/2017 